pag

Business School

WORKING PAPER SERIES

Working Paper

2014-143
Co-movements between Germany and International Stock Markets: Some New Evidence from DCC-GARCH and Wavelet Approaches

Gazi Salah Uddin

Mohamed Arouri

Aviral Kumar Tiwari

http://www.ipag.fr/fr/accueil/la-recherche/publications-WP.html

IPAG Business School

184, Boulevard Saint-Germain

75006 Paris

France 


\title{
Co-movements between Germany and International Stock Markets: Some New Evidence from DCC-GARCH and Wavelet Approaches
}

\author{
Gazi Salah Uddin \\ Linköping University, Sweden \& IPAG Business School, France \\ Email: gazi.salah.uddin@liu.se \\ Mohamed Arouri \\ EDHEC Business School, France \\ E-mail: Mohamed.arouri@u-clermont1.fr \\ Aviral Kumar Tiwari \\ ICFAI University, India \\ E-mail: aviral.eco@gmail.com
}

\begin{abstract}
The analysis of co-movements of stock market returns is a fundamental issue in finance. The aim of this paper is to examine the co-movement between Germany and major International Stock Markets in the time-frequency space. Our sample period goes from 01 June 1992 to 26 March 2013 and includes the financial crisis that erupted in US financial institutions in the summer of 2007 and spread beyond the US to other developed economies in the first half of 2008. We use DCC-GARCH and wavelet-based measures of co-movements which make it possible to find a balance between the time and frequency domain features of the data. The results suggest that the difference in the co-movement dynamics could be the result of the different natures of the financial crises or a change in regime. The finding of this paper has relevant policy implications in asset allocation and risk management in designing international portfolios for investment decisions.
\end{abstract}

Keywords: DCC-GARCH; Co-movement; Wavelet coherence; Germany

JEL classification: G15; C40; F30 


\section{Introduction}

Studying international stock market co-movements is an ongoing issue in the finance literature that has important implications for risk management and investment decisions. Advantages of portfolio diversification in the domestic market were documented by Markowitz (1952) and motivated by low correlations among domestic assets. International diversification leads to higher return and lower risk compared to domestic diversification [Grubel (1968) and Grauer and Hakansson (1987)]. Therefore, investors should invest not only in the domestic market but also in the international stock market. Moreover, it is now well known that stock market co-movements are not constant but change over time. There has been a large group of researchers who are working on the strength of stock market comovements. Overall, previous works show that international stock market co-movements have increased over time [Hilliard (1979) and Kizys and Pierdzioch (2009)].

However, most of the recent work analyzing stock markets co-movements has been based on time domain aspect of analysis and ignored frequency domain. Rua and Nunes (2009) claims that the higher strength in the co-movements of stock returns at lower frequencies suggesting higher return from international diversification in the short-term relative to the long-term. However, stock markets are complex systems of interacting investment agents with different term objectives. Hence, time series resulting from this process are formed by a combination of different components operating at different frequencies. Therefore, the standard time series econometric method which considers the frequency and time components separately usually looses one side of information. Specifically, studies based on time series analysis loses frequency aspect and studies based on frequency domain lose the time aspect.

Compared to previous contribution on stock market co-movements, we propose a method which has good balance between time and frequency aspect of the data. To be specific, we introduce the wavelet approach, which allows us to study the frequency components of time series without losing the time information. This method helps us to uncover stock market interactions those are hard to see using any other modern econometric method and which would otherwise had remain hidden. Another advantage is that the wavelet analysis approach is model-free which make it more powerful tool to analyse in comparison to the other time series or frequency based estimation methods as those are based on parameters as well as estimation method.Thus the wavelet application in the stock market co-movement can provide several insights into changing patterns of stock market co-movements which will enable simultaneous assessment of short term and long term stock market co-movements and detects change in market linkages over time.

The aim of this paper is to examine the strength of the co-movement between Germany, the center of the euro area, and four major international stock markets (the US, Canada, Japan, Australia) in the time and frequency space by resorting to wavelet analysis using daily data from 01 June 1992 to 26 March 2013. The wavelet method results are relatively easy to interpret and offer considerable amount of information on co-movements and led-lag relationships among the stock markets encompassing time as well as frequency domain aspects within. Moreover, this approach permits to evaluate co-movements across different 
investment horizons and to distinguish between short term and long term investors. To relate our findings to the standard econometric literature, we connect our approach with the standard econometric approach of (Engle, 2002) - dynamic conditional correlations from a multivariate DCC-GARCH model in order to measure the co-movements between Germany and major international stock markets.. Our main findings show a clear pattern of comovements at higher frequencies in all markets during the turbulent period of the 2007-2009 financial crises. Variation across markets co-movements are found at different frequency levels. The importance of these findings highlights the time and frequency varying features of the co-movements in designing international portfolios.

The paper proceeds as follows. The next section gives a literature review on stock market comovements. The data construction is explained in Section III. Section IV introduces the wavelet-based measure of co-movement, while Section $\mathrm{V}$ discusses empirical results. The final section brings together the key findings and makes some concluding remarks.

\section{Literature Review}

There are different approaches to examine co-movement of international financial markets. First, the rolling window approach is commonly used to assess co-movement of stock returns (Brooks and Del Negro, 2004). Second, another important part of the literature argues that comovement in the time domain is not similar with co-movement in the frequency domain. Frequency domain analysis intensively used to investigate the co-movement at the frequency level [A'Hearn and Woitek (2001) and Pakko (2004)] by utilizing the Fourier method (see, Rua and Nunes (2005)). However, the shortcoming of the frequency domain explains the comovement at the frequency level but fails in capturing time-varying features in the series. Third, the multivariate analysis techniques used to investigate the financial integration through integration and principal component analysis. Applying the co-integration testing procedure, Taylor and Tonks (1989) find evidence of co-integration between stock prices in the UK, Germany, the Netherlands and Japan but not the USA.

The analysis in the frequency domain is missing in the literature. The relations may found at the different frequencies: like short, medium and long term. Earlier studies do not concentrate their analysis in the frequency and scale domains, where as it is fundamentally important in the financial market integration. This approach investigates not only the relations at the different frequencies and its change over time. The application of the wavelet approach is introduced in Finance and Economics by the pioneer work of Ramsey and Zhang (1996, 1997) and Ramsey and Lampart (1998a, b). Fernandez (2005, 2006) established the importance of wavelets analysis for managing risk and provides diversification for investment decisions. Tiwari (2012) use the cross wavelet, wavelet coherency and phase-difference to study the time-frequency effects of oil price changes on the German macro-economy. The results show that there are both phase and anti-phase relationships between oil price returns and inflation and inflation are the leading variable and there is a huge inconsistency between 
the phase-difference of the return series of oil price and industrial production. The wavelet coherency offers a refinement on variables co-movements and measuring their dependences.

In the application of stock market integration literature, using the wavelet approach Rua and Nunes (2009) and Ranta (2009) find that co-movement the returns series of stock market indices of Germany, Japan, the UK, and the US varies in time-frequency framework across countries and strength of co-movement is stronger at lower frequencies. Rua (2010) documented that wavelet approach allows in assessing, simultaneously, the co-movement of the variables at various frequencies across time. Utilizing this approach one can easily capture the time and frequency varying features of co-movement within a unified framework which constitutes a refinement to previous approaches. Using the same approach, Tonn et al. (2010) examines the relations between futures prices of natural gas and oil. The findings of their paper reveal that the prices of natural gas futures and oil futures have high covariance at high frequencies but not so much at low frequencies. Utilizing continuous wavelet transform, in a recent study, Rua and Nunes (2012) suggested a novel approach to measuring market risk. Risk is allowed to vary both through time and at the frequency level within a unified framework which highlights the usefulness of the wavelet approach. Utilizing similar approach of linear and non-linear causality Tiwari et al. (2013) for India-U.S. Dollar exchange rate and oil price found bidirectional causal relationships between the oil price and the real effective exchange rate of Indian rupee at higher time scales. Recently, using the continuous wavelet procedure, Uddin and Tiwari (2013) investigate the change in the real exchange rate and oil price differential for Bangladesh. They suggest that cycle of 32 month and more, less convincing evidence of coherence are sustained between the change in real oil price and exchange rate in Bangladesh.

Vacha and Barunik (2012) examine the application of wavelet tools to commodity market data. Using wavelet coherence, they uncovered interesting dynamics of correlations between energy commodities in the time-frequency space. Akoum (2012), using wavelet coherence, examines the short term and long term dependencies between stock market returns and OPEC basket oil returns for the six Gulf Cooperation Council (GCC) countries (Bahrain, Kuwait, Oman, Qatar, Saudi Arabia, and the United Arab Emirates) and two non-oil producing countries in the region (Egypt and Jordan), over the period 2002-2011. They claim that an increasing strength in the market dependencies after 2007, signifying enhanced diversification benefit for investors in the short term relative to the long term.

Apply the three-dimensional analysis of wavelet coherency, Graham et al. (2012) examine the integration of 22 emerging stock markets with the U.S. market. Their study find a high degree of co-movement at relatively lower frequencies between the U.S. and the 22 individual emerging markets. The strength of co-movement, however, differs by country. KIviaho et al., (2012) used wavelet approach and found that the strength of co-movement varies considerably across the frontier markets, at different frequencies (time horizons) and over time. Their results provide evidence that the co-movement is relatively weaker for the frontier markets of Central and Southeastern Europe than in the Baltic region. In addition, the documents that the co-movement is stronger at lower frequencies (longer horizons) and increases during the turbulent period of the global financial crisis of 2008. Applying a 
Dynamic Conditional Correlation-Generalized Autoregressive Conditional Heteroskedastic (DCC-GARCH) and wavelet multi-scale analysis on a daily return series for the period 1997 to 2010, Dajcman et al. (2012) examines the co-movement dynamics between the developed European stock markets of the United Kingdom, Germany, France and Austria. The author's find that the co-movements between stock market returns are time varying and scale dependent and financial crisis in the observed period did not uniformly increase co-movement between stock market returns across all scales. The author's claim that the global financial crisis of 2007-2008 only slightly and temporarily increased the already high level of comovement between the observed stock markets. Loh (2013) finds the synchronization between most of the Asia-Pacific stock markets and that of Europe and the US in the long run and provide evidence of a wide variation in the co-movement across the time-scale of the financial crises. The dynamics of the co-movement could be the result of the different natures of the financial crises or a change in the economic regime.

\section{Data Construction}

In order to get a sufficient number of observations for a wavelet analysis in combination with a relevant data sample in time, it is suitable to work with daily data. Daily stock market indices, NASDAQ and NYSE composite price index for USA, S\&P/TSX composite price index for Canada; S\&P/ASX 200 price index for Australia; NIKKEI 225 price index for Japan; Hong Kong and DAX 30 price index for Germany were collected from Thompson Datastream for the period 01 June 1992 to 26 March 2013. The computations were done with daily stock returns, defined as the log first difference of monthly stock price indices. In this paper, we use returns denominated in the home currency of each respective country. The wavelet computations were completed in Matlab ${ }^{1}$.

Figure 1: Return series

\footnotetext{
${ }^{1}$ The codes are available on request.
} 

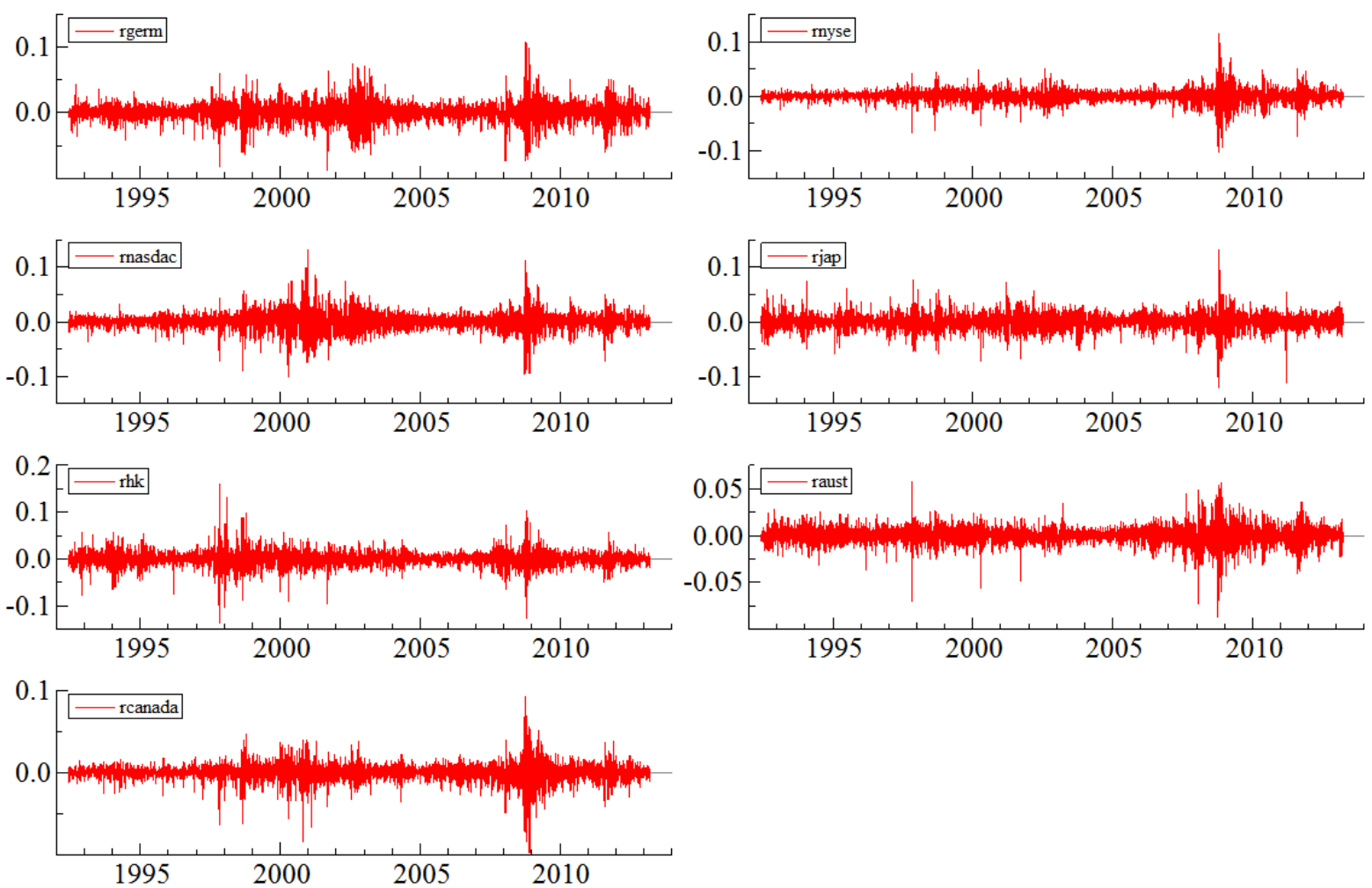

Table 1: Descriptive Statistics

Panel A: Summary Statistics

\begin{tabular}{|l|l|l|l|l|l|l|l|}
\hline & Germany & NYSE & NASDAQ & Japan & Hongkong & Australia & Canada \\
\hline Mean & 0.0003 & 0.0002 & 0.0003 & -0.0001 & 0.0002 & 0.0002 & 0.0002 \\
\hline Median & 0.0005 & 0.0003 & 0.0006 & 0.0000 & 0.0000 & 0.0001 & 0.0004 \\
\hline Std. Dev. & 0.0146 & 0.0115 & 0.0156 & 0.0148 & 0.0159 & 0.0096 & 0.0106 \\
\hline Skewness & -0.1213 & -0.3919 & -0.0611 & -0.2115 & -0.0348 & -0.4633 & -0.7390 \\
\hline Kurtosis & 7.6811 & 14.0931 & 8.9054 & 8.9764 & 11.5184 & 9.1132 & 13.4624 \\
\hline Jarque-Bera & 4971.94 & 27985.50 & 7895.10 & 8123.11 & 16421.66 & 8651.11 & 25264.46 \\
\hline Probability & 0.0000 & 0.0000 & 0.0000 & 0.0000 & 0.0000 & 0.0000 & 0.0000 \\
\hline Observations & 5431 & 5431 & 5431 & 5431 & 5431 & 5431 & 5431 \\
\hline
\end{tabular}


Panel B: Unconditional correlations of $r_{i t}$

\begin{tabular}{|l|l|l|l|l|l|l|l|}
\hline & Germany & NYSE & NASDAQ & Japan & Hongkong & Australia & Canada \\
\hline Germany & 1 & & & & & & \\
\hline NYSE & $\mathbf{0 . 5 6 3 3}$ & 1 & & & & & \\
\hline NASDAQ & 0.4875 & $\mathbf{0 . 8 0 1 0}$ & 1 & & & & \\
\hline Japan & 0.2523 & 0.1382 & 0.1052 & 1 & & & \\
\hline Hongkong & 0.3218 & 0.1841 & 0.1524 & 0.4270 & 1 & & \\
\hline Australia & 0.2941 & 0.1609 & 0.1075 & 0.5070 & 0.5106 & 1 & \\
\hline Canada & 0.4990 & $\mathbf{0 . 7 3 1 0}$ & 0.6643 & 0.1994 & 0.2322 & 0.2163 & 1 \\
\hline
\end{tabular}

Notes: The test for Kurtosis coefficient has been normalized to zero. JB is the Jarque-Bera test for normality based on excess skewness and Kurtosis. *, ** and *** indicate significance of coefficients at the $1 \%, 5 \%$ and $10 \%$ respectively.

Panel A summarizes the summary statistics for the daily return. Hong Kong has the highest standard deviation followed by the NASDAQ market, Japan and Germany, where Australia has the lowest standard deviation followed by Canada and NYSE. Germany and NASDAQ has the highest monthly return whereas Japan has the lowest mean. Skewness is mostly negative and kurtosis is above three. The Jarque-Bera test statistic (JB) strongly rejects the hypothesis of normally distributed returns. These facts support our decision to use the quasimaximum likelihood (QML) approach of Bollerslev and Wooldridge (1992) to estimate and test the model.

Panel B reports the unconditional correlations among markets. As expected, there is a positive correlation between stock markets. The highest unconditional correlation is between NYSE and NASDAQ (0.80) followed by the correlation between Canada and NYSE and NASDAQ. This implies regional markets are more connected each other. The correlation between Germany and NYSE and NASDAQ is 0.49 and 0.25 respectively. The lowest correlation is between NASDAQ and Australia (0.11). The values of the unconditional correlations are somewhat low. This suggests that there are still benefits from diversification across the world.

\section{Methodology}

In this section we will discuss in brief the econometric methodology we will employ in our research work. First approach will be used is wavelet analysis. In wavelet analysis we will rely on wavelet power spectrum, cross-wavelet analysis, wavelet coherency and phase- 
differences. The wavelet power spectrum demonstrates the volatilities and spikes in the data series; cross-wavelet analysis can be interpreted as co-variance of time series analysis; wavelet coherency can be interpreted as correlation in the time series analysis; and phasedifference provide the evidence of lead-lag relationship. The second approach that we will use it the DCC GARCH model to compare the unconditional co-correlation with the conditional correlation and finally compare our results obtained from both approaches. One should note that our both approaches has similarity in the sense that they show time-varying correlation over period of time. However, whereas DCC GARCH approach shows timevarying correlation over period of time in two dimension WTC approach shows the same in three dimensions. Another, dissimilarity is that whereas DCC GARCH approach provides a single correlation coefficient for a point of time using WTC approach one can compute several correlation coefficients for a point of time but by varying frequencies.

\subsection{A Wavelet-based Measure of Synchronization}

The wavelet transform decomposes a time series in terms of a wavelet function $\psi_{\varphi}(\mathrm{t})$ that depends on time parameter t. Following Rua and Nunes (2009), we use a continuous-time Morlet wavelet $\psi_{\varphi}(\mathrm{t})$ with a frequency parameter that is equal to 6 . The continuous wavelet transform $W_{t}^{X a}(r)$ of a discrete sequence $x_{m}, m=1, \ldots, M-1, M$ with uniform time steps $\varphi \mathrm{t}$ is defined as the convolution of $\mathrm{x}_{\mathrm{m}}$ with the scaled and normalized wavelet. The description of continuous wavelet transform is heavily drawn from Grinsted et al. (2004). The equation can be written as

$\mathrm{W}_{\mathrm{t}}^{\mathrm{Xa}}\left(\mathrm{r}_{\mathrm{s}}\right)=\sqrt{\frac{\varphi \mathrm{t}}{\mathrm{r}}} \sum_{\mathrm{t}=1}^{\mathrm{M}} \mathrm{X}_{\mathrm{m}^{\prime}} \Psi_{\varphi}\left[\left(\mathrm{m}^{\prime}-\mathrm{m}\right) \frac{\varphi \mathrm{t}}{\mathrm{r}}\right]$

where $\varphi$ is the time step (Torrence and Compo 1998).The wavelet power is defined as $\left|\mathrm{W}_{\mathrm{t}}^{\mathrm{Xa}}\left(\mathrm{r}_{\mathrm{s}}\right)\right|^{2}$. Since our intention is to measure the extent of synchronization between two given time series, it is informative to use coherence between them. Fourier spectral approaches defined Wavelet Coherency (WTC) as the ratio of the cross-spectrum to the product of each series' spectrum furthermore can be taught of as the local correlation between two time series, both in time and frequency. Given two countries economic activity time series $X_{m}$ and $Y_{m}$ with the wavelet transforms $W_{t}^{X a}\left(r_{s}\right)$ and $W_{t}^{Y b}\left(r_{s}\right)$ respectively, we can defined the cross-wavelet spectrum as $\mathrm{W}_{\mathrm{t}}^{\mathrm{XaYb}}\left(\mathrm{r}_{\mathrm{s}}\right)=\mathrm{W}_{\mathrm{t}}^{\mathrm{Xa}}\left(\mathrm{r}_{\mathrm{s}}\right) * \mathrm{~W}_{\mathrm{t}}^{\mathrm{Yb} *}\left(\mathrm{r}_{\mathrm{s}}\right)$. Following Torrence and Webster (1999), the Wavelet Coherence of two time series can be defined as,

$\mathrm{R}_{\mathrm{t}}^{2}\left(\mathrm{r}_{\mathrm{s}}\right)=\frac{\left|\mathrm{Q}\left(\mathrm{r}_{\mathrm{s}}{ }^{-1} \mathrm{~W}_{\mathrm{t}}^{\mathrm{XaYb}}\left(\mathrm{r}_{\mathrm{s}}\right)\right)\right|^{2}}{\vartheta\left|\left(\mathrm{r}_{\mathrm{s}}{ }^{-1}\left|\mathrm{~W}_{\mathrm{t}}^{\mathrm{Xa}}\left(\mathrm{r}_{\mathrm{s}}\right)\right|^{2}\right)\right| \cdot \mathrm{Q}\left|\left(\mathrm{r}_{\mathrm{s}}{ }^{-1} \mid \mathrm{W}_{\mathrm{t}}^{\mathrm{Yb}}\left(\mathrm{r}_{\mathrm{s}}\right)^{2}\right)\right|}$ 
Where, $\vartheta$ is considered as a smoothing operator (Rua and Nunes 2009). In equation 2, the numerator is the absolute value squared of the smoothed cross-wavelet specturum and denominator represents the smoothed wavelet power spectra (Torrence and Webster 1999; Rua and Nunes 2009). The value of the wavelet squared coherency $R_{t}^{2}\left(r_{s}\right)$ gives a quantity between 0 and unity, with a large value showing high co-movement between two stock market and vice versa. However, positive value is only considering the wavelet squared coherency which is not similar in correlation coefficient. The robustness of this approach is that it enables us to identify area of co-movement between two series in the time frequency space and significance of the wavelet coherence measured by the Monte Carlo simulation methods (Torrence and Compo (1998). In this present study will focus on the Wavelet Coherency, instead of the Wavelet Cross Spectrum in following the study by Aguiar-Conraria and Soares (2011).

\subsection{Modeling dynamic conditional correlation}

Most previous works that assess time-varying correlation between stock markets rely on the multivariate DCC model developed by Engle (2002) This model is suitable to assess comovements between the markets we study because it allows us to directly infer the crossmarket conditional correlations.

Assume that stock market returns from the $k$ series are multivariate normally distributed with zero mean and conditional variance-covariance matrix $H_{t}$, our multivariate DCC-GARCH model can be presented as follows:

$\left\{\begin{array}{l}r_{t}=\mu_{t}+\varepsilon_{t}, \varepsilon_{t} \mid I_{t-1} \rightarrow N\left(0, H_{t}\right) \\ H_{t} \equiv D_{t} R_{t} D_{t}\end{array}\right.$

In these formulas, $r_{t}$ is the $(k \times 1)$ vector of the returns on stock market indices; $\varepsilon_{t}$ is a $(k \times 1)$ vector of zero mean return innovations conditional on the information available at time $t-1$; $\mu_{i, t}=\delta_{i 0}+\delta_{i 1} r_{i, t-1}$ for market $i ; D_{t}$ is a $(k \times k)$ diagonal matrix with elements on its main diagonal being the conditional standard deviations of the returns on each market in the sample and $R_{t}$ is the $(k \times k)$ conditional correlation matrix and. $D_{t}$ and $R_{t}$ are defined as follows:

$D_{t}=\operatorname{diag}\left(h_{11 t}^{1 / 2} \ldots h_{k k t}^{1 / 2}\right)$

where $h_{i i t}$ is chosen to be a univariate $\operatorname{GARCH}(1,1)$ process;

$R_{t}=\left(\operatorname{diag} Q_{t}\right)^{-1 / 2} Q_{t}\left(\operatorname{diag} Q_{t}\right)^{-1 / 2}$

where $Q_{t}=(1-\alpha-\beta) \bar{Q}+\alpha u_{t-1} u_{t-1}^{\prime}+\beta Q_{t-1}$ refers to a $(k \times k)$ symmetric positive definite matrix with $u_{i t}=\varepsilon_{i t} / \sqrt{h_{i i t}}, \bar{Q}$ is the $(k \times k)$ unconditional variance matrix of $u_{t}$, and $\alpha$ and $\beta$ are nonnegative scalar parameters satisfying $\alpha+\beta \prec 1$. 
The conditional correlation coefficient $\rho_{i j}$ between two markets $i$ and $j$ is then expressed by the following equation:

$$
\rho_{i j}=\frac{(1-\alpha-\beta) \bar{q}_{i j}+\alpha u_{i, t-1} u_{j, t-1}+\beta q_{i j, t-1}}{\left((1-\alpha-\beta) \bar{q}_{i i}+\alpha u_{i, t-1}^{2}+\beta q_{i i, t-1}\right)^{1 / 2}\left((1-\alpha-\beta) \bar{q}_{j j}+\alpha u_{j, t-1}^{2}+\beta q_{j j, t-1}\right)^{1 / 2}}
$$

In this formulation, $q_{i j}$ refers to the element located in the ith row and $j$ th column of the symmetric positive definite matrix $Q_{t}$. Accordingly, the estimation of the DCC-GARCH model as described above is can be estimated using a two-stage procedure. In the first stage, univariate GARCH $(1,1)$ model is estimated for each time series. During the second stage, the transformed residuals from the first stage (i.e., the estimated residuals are standardized by their conditional standard deviations) are used to infer the conditional correlation estimators. The log-likelihoodof the observations on $\varepsilon_{t}$ is given by

$$
L=-\frac{1}{2} \sum_{t=1}^{T}\left(n \log (2 \pi)+\log \left|D_{t} R_{t} D_{t}\right|+\varepsilon_{t}^{\prime} D_{t}^{-1} R_{t}^{-1} D_{t}^{-1} \varepsilon_{t}\right)
$$

Since $u_{t}=\varepsilon_{t} / \sqrt{h_{t}}=D_{t}^{-1} \varepsilon_{t}$, the log-likelihood function can be rewritten as follows:

$$
L=-\frac{1}{2} \sum_{t=1}^{T}\left(n \log (2 \pi)+2 \log \left|D_{t}\right|+\log \left|R_{t}\right|+u_{t}^{\prime} R_{t}^{-1} u_{t}\right)
$$

Note that a conditional variance term can be added into the mean equation to control for the risk-return tradeoffs in previous works. However, the majority of these studies found evidence of insignificant impact of conditional volatility on stock returns. Lundblad (2007) studied the same issue over the period from 1802 to today and concluded that the mean-variance tradeoffs are only positively significant over a long-term horizon. Accordingly, we intentionally do not model the in-mean effect of conditional volatility because we focus on a short-run comovement between stock and bond markets ${ }^{2}$.

\section{Empirical Findings of the analysis}

\subsection{Empirical Findings of the Wavelet application}

First we will present results of wavelet coherency and phase-relationship between Germany and other major international stock markets and in next we will present results of DCCGARCH model. While reporting the results of the dynamics of the stock return co-movement obtained by applying the cross-wavelet coherency approach we used three dimensional graphs. The frequency represents on the vertical axis and expressed in time units (days). The time is depicted in horizontal axis (daily). Figure 2 presents the estimated wavelet coherency

\footnotetext{
${ }^{2}$ We effectively attempted to estimate our model with the in-mean volatility effects in the return generating processes and the results are consistent with our intuition and Lundblad (2007)'s findings.
} 
and phase relationship between Germany and the four indices namely US, Canada, Japan and Australia. These are the market is well established market in the region based on their market capitalization. The significance is obtained through Monte Carlo simulations. Contours denote wavelet-squared coherency, the thick black contour is the $5 \%$ significance level and outside of the thin line is the boundary affected zone.

Figure 2: Wavelet Coherence Germany with Major Stock market

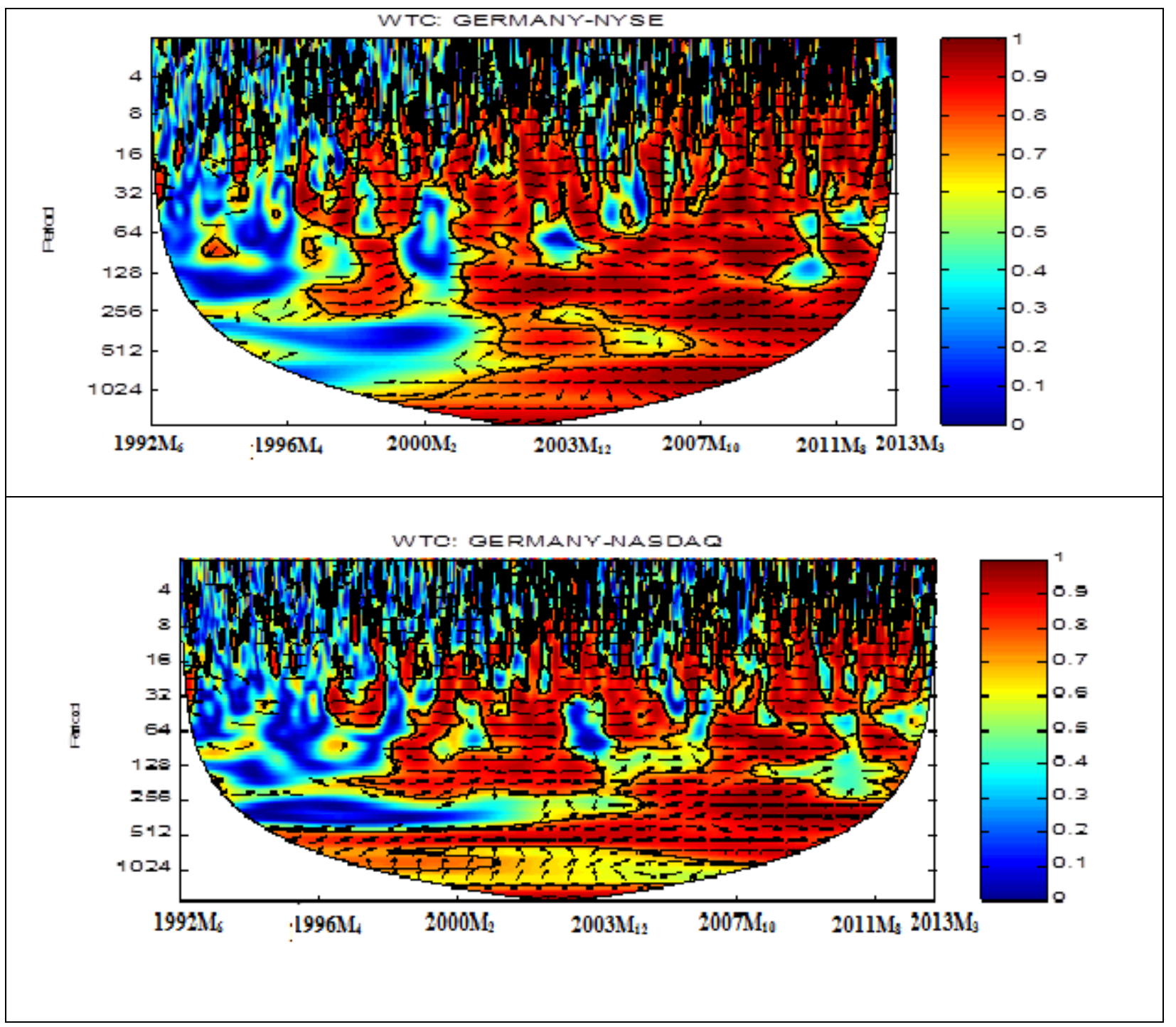




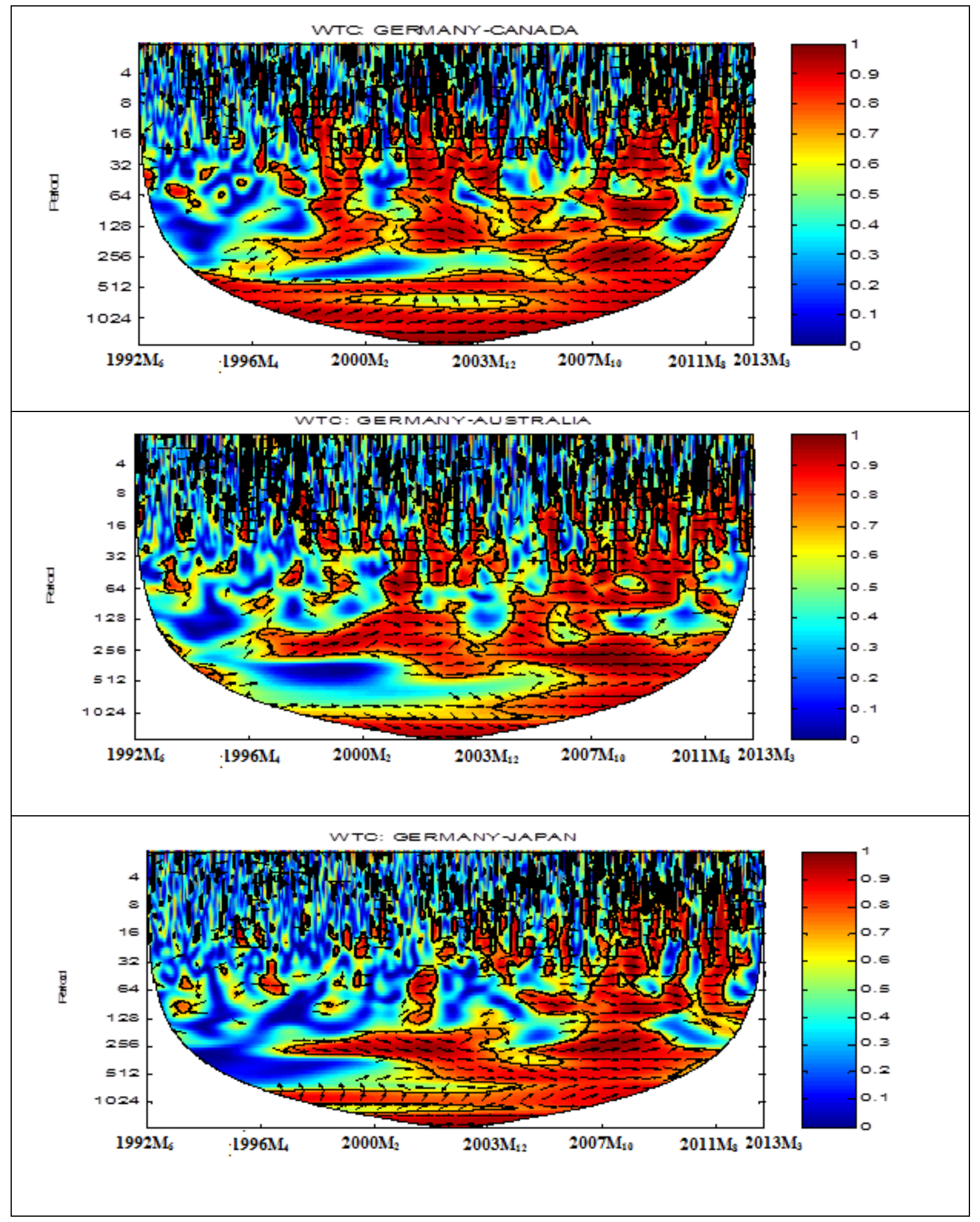




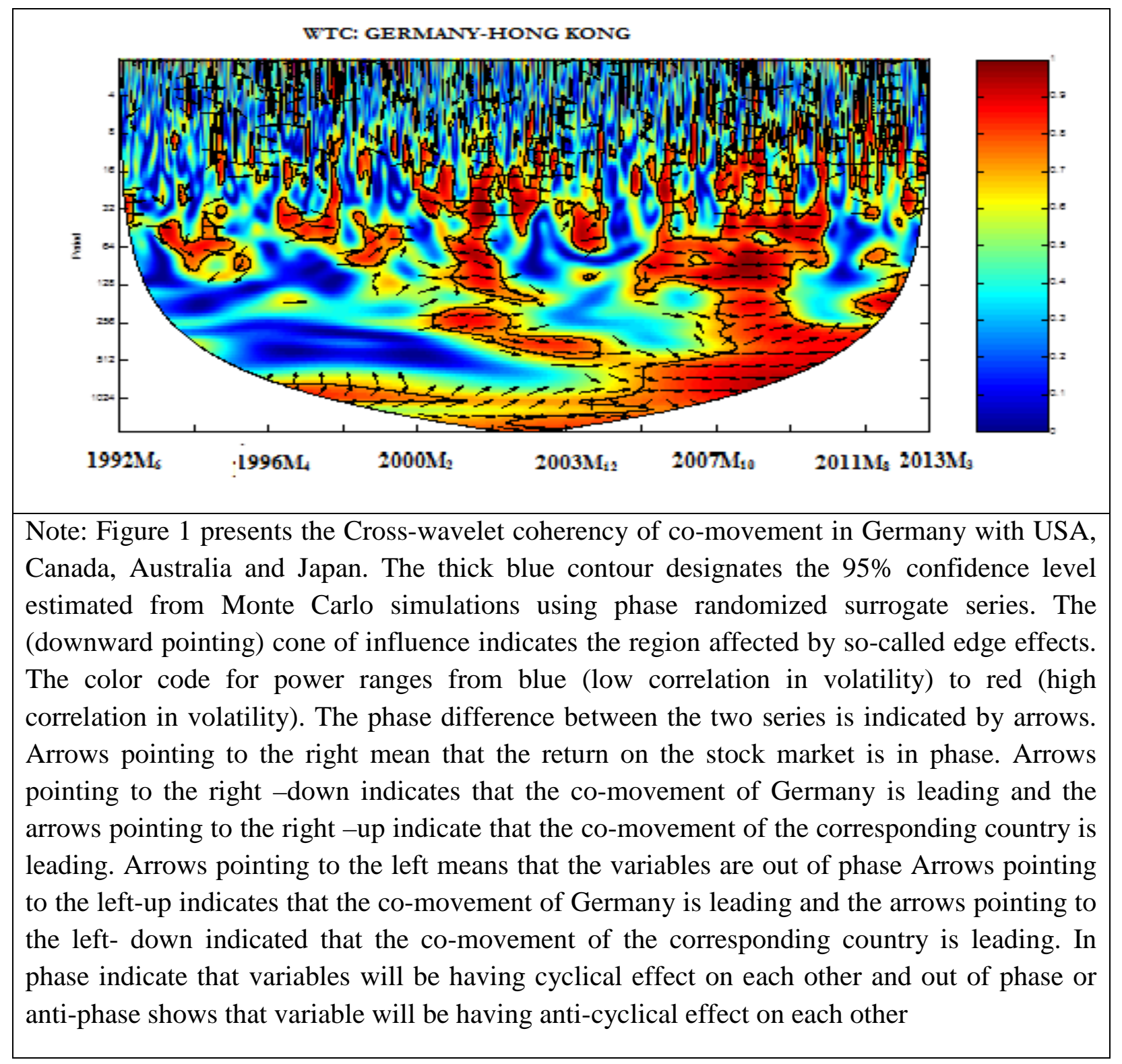

In the cross-wavelet power pictures, color code for power ranges from blue (low coherency) to red (high coherency). Vectors indicate the phase difference between the two series. Information on the phases shows us that the relationship among stock market indices was not homogeneous across scales, since arrows point right and left, down and up constantly. Moreover, the cross wavelet coherency is high at low frequencies, but in the highest scale of all, most of the coherence results are not statistically significant since they rely below the cone of influence. The three dimensional setting enables us to detect areas of varying comovement among return series over time across frequencies. The areas of stronger comovement in the time-frequency space imply lower benefits from international portfolio diversification.

Information on the phases shows us that the relationship among stock market indices was not homogeneous across scales, since arrows point right and left, down and up constantly. Moreover, the cross wavelet coherency is high at low frequencies, but in the highest scale of 
all. The wavelet cross-coherency shows low-to-medium statistically significant coherence, but we are still able to observe some islands of medium power, mostly during the 11th September 2001 terrorist attack and the 2007-2009 current financial crisis for most of the indices.

From the analysis of the result obtained in figure 1, Germany presents a relatively high degree of co-movement at lower to higher frequencies at the end of the 2000. Since, this high degree of co-movement has been extended to all frequencies. The strong co-movement is confined to long run fluctuations while afterwards it is visible for all sorts of fluctuations.

Between 1996 and 2000, the relationship between Germany and NYSE and NASDAQ was very strong. Phase (with arrows being straight lines and pointing right) information shows that there is high coherency among the return on stock indices on the daily time scales bands of 16-256 days band. This suggests that both series were strongly correlated and in phase during the period of the Asian and Russian financial Crisis and Crisis and Brazilian currency crises (Forbes \& Rigobon, 2002; Kenourgios et al., 2011). During the terrorist Attacks in the USA, Madrid, Iraq Invasion and Financial crisis between 2001 and 2011, there is strong comovement between Germany and NYSE and NASDAQ. The findings are also consistent with the earlier findings (Hon et al., 2004). Phase (with arrows being straight lines and pointing right) information shows that there is high coherency among the return of stock indices on the daily time scales bands of 32-1024 days band. The impact of the 2008-09 financial crises on foreign stock markets found the earlier literature (Schwert, 2011; Syllignakis \& Kouretas, 2011).During the Iraq invasion between the cycles of 2003 and 2005s, in the cross-coherency and phase plot between Germany and NYSE we are able to observe that Germany is leading (with arrows are pointing right and being down) to NYSE at the frequencies 1024-above days band. This finding provides additional insights on the fact, commonly found in the recent literature, that there has been overall increasing co-movement.

With regard to the co-movement of Germany and Canada, we find considerable variation in the co-movement pattern across the countries. The time interval between 1998 and 2000, Germany shows strong co-movement with the Canada at the low frequencies throughout the sample period. Phase relationship between Germany and Canada shows that there is high coherency among the stock indices on the daily time scales bands of 20-70 days band. The strengthening effect may be due to greater market interdependence in phase during the period of the Asian and Russian financial Crisis and Crisis and Brazilian currency crises (Forbes \& Rigobon, 2002; Kenourgios et al., 2011). This is to be expected, given that during the collapse of the Dot-Com bubble and the accounting scandals in the US, who contributed to a relatively mild contraction in the North American Economy; US Elections; Terrorist Attacks in the USA; between 2001 and 2004, there is a strong co-movement between Germany and Canada. There is an evidence of co-movement between these two countries information and shows that there is high coherency among the return on stock indices on the daily time scales bands of 16-200 days band. This is not surprising that the findings between Germany with US and Germany with Canada are similar. Canadian trade and economic dependencies with US is significantly high. Charles and Darne' (2006) investigate the effects of the terrorist attacks in US on September 11, 2001, on international stock markets and found that US 
macroeconomic news announcements can have a great impact on the US and European stock markets by detecting large shocks.Concerning the co-movements during the period between 2008 and 2011, the findings provide an evidence of strong co-movement between Germany and Canada at the daily time scales bands of 16-128 days band. This suggests that international stock markets co-movement is high during the global financial crisis period which is consistent with the findings of Longin and Solnik (1995) and Cheung et al. (2010). The financial crisis erupted in US financial institutions in the summer of 2007 and spread beyond the US to other developed economies in the first half of 2008 (Uddin and Bo, 2013).

The pattern of strong co-movement between Germany and Canada during the period 1994 to 2009 at the daily time scales bands of 512-above days band. This result suggests that international stock market integration as a result of the 1997 Asian financial crisis, Brazilian crisis and Russian crisis (Forbes \& Rigobon, 2002; Kenourgios et al., 2011).The terrorist acts in New York and Washington took place on September 11, 2001 and WorldCom revealed its great accounting fraud on June 25, 2002. The US stock market was also heavily influenced by a slowdown of the American economy (Hon et al., 2004 and Kenourgios et al., 2011). The impact of the 2008-09 financial crises on international stock market found the earlier literature (Chudik \& Fratzscher, 2011; Schwert, 2011; Syllignakis \& Kouretas, 2011).The cycles between 2007 and 2010s, in the cross-coherency and phase plot between Germany and Canada we are able to observe that Canada is leading to Germany at the frequencies 200-400 days band. The collapse of the housing market led to bank collapses in the US and Europe, causing the amount of available credit to be sharply curtailed, resulting in massive liquidity and solvency crises. In addition to high oil prices, stock markets crashed worldwide and a banking collapse took place in the United State.

With regard to the co-movement between Germany and Asian giant financial market Japan, the third largest stock market in the world, we find a considerable variation in the comovement between these countries. The strong co-movement between Germany and Japan during the period 2006 to 2011, there is an evidence of stock return co-movement between thsese two indices at the daily time scales bands of 32-512. The terrorist acts in New York and Washington took place on September 11, 2001 and World Com revealed its great accounting fraud on June 25, 2002. The US stock market was also heavily influenced by a slowdown of the American economy (Hon et al., 2004 and Kenourgios et al., 2011). The impact of the 2008-09 financial crises on international stock market found the earlier literature (Syllignakis \& Kouretas, 2011). During the cycles of 1996 and 2002s, in the crosscoherency and phase plot between Germany and Japan, we are able to observe that Germany is leading to Japan at the frequencies 200-500 days band. The study by, Awokuse et al. (2009) investigate the interdependence of Asian, Japan, US and UK markets using cointegration methods, finding evidence for an increase in international stock market integration as a result of the 1997 Asian Financial crisis. The dates for the financial collapses in Russia and Brazil are based on Rigobon (2003). The initial shock to the Russian financial markets took place on August 6, 1998, and persisted till the end of September. The pattern of co-movement during the cycles of 1996 and 2008s, in the cross-coherency and phase plot between Germany and Japan, we are able to observe that Japan is leading to Japan at the 
frequencies 200-500 days band. The co-movement between Germany and another Asian giant financial market Hong Kong, we didn't find a considerable variation in the co-movement between these countries. The strong co-movement between Germany and Hong Kong during the period 2006 to 2011, there is an evidence of stock return co-movement between these two indices at the daily time scales bands of 32-1024.

Turning to our attention on the co-movement between Germany and Australia during the period 1996 to 2002, there is a phase relationship between these two markets and market information shows that there is high coherency among the stock indices on the daily time scales bands of 100-384 days band. This finding is similar with the earlier findings Germany with US, Canada and Japan. This suggests that both series were strongly correlated during the period of the Asian financial crisis, Russian financial crisis, and terrorist attacks in the USA. There is a phase relations between these two countries between 2004 and 2008 at the daily time scales bands of 32-1024 days band. This suggests that both series were strongly correlated during the period of the OPEC Cut Agreement and starting the financial crisis in US. The nature of the co-movement relationship between Germany and Australia was very strongly in phase relationship. There is an evidence of Phase relationship in high coherency among the return of stock indices on the daily time scales bands of 256-1024 days band during the period 2007 and 2012. This suggests that both series were strongly correlated during the period of the financial crisis and post financial crisis period and US national election. During the cycles of 1998 and 2003s, in the cross-coherency and phase plot between Germany and Australia we are able to observe that Germany is leading to Japan at the frequencies 1024-above days band. This result suggests that international stock market integration as a result of the 1997 Asian financial crisis, Brazilian crisis and Russian crisis (Forbes \&Rigobon, 2002; Kenourgios et al., 2011). The terrorist acts in New York and Washington took place on September 11, 2001 and World Com revealed its great accounting fraud on June 25, 2002. The US stock market was also heavily influenced by a slowdown of the American economy (Hon et al., 2004 and Kenourgios et al., 2011).

\subsection{Empirical findings of the DCC-GARCH application}

In this paper, the purpose to rely on the time-varying correlation coefficients estimated from a multivariate DCC-GARCH model developed by Engle (2002) to measure the comovements between Germany and major top stock markets in the world stock market. 
Table 2: DCC GARCH Estimation results

Panel A - parameter estimates-mean equations

\begin{tabular}{|l|l|l|l|l|l|l|l|}
\hline & Germany & NYSE & NASDAQ & Japan & Hongkong & Australia & Canada \\
\hline$\delta_{0}$ & $0.0007^{*}$ & $0.0005^{*}$ & $0.0007^{*}$ & $0.0003^{* *}$ & $0.0005^{*}$ & $0.0004^{*}$ & $0.0005^{*}$ \\
& $(0.0001)$ & $(0.0001)$ & $(0.0001)$ & $(0.0001)$ & $(0.0001)$ & $(0.0001)$ & $(0.0001)$ \\
\hline$\delta_{1}$ & -0.005 & 0.0156 & $0.0245^{* * *}$ & $-0.0237^{* * *}$ & $0.0593^{*}$ & 0.0009 & $0.0840^{*}$ \\
& $(0.000)$ & $(0.2671)$ & $(0.0137)$ & $(0.0138)$ & $(0.0000)$ & $(0.4998)$ & $(0.0143)$ \\
\hline
\end{tabular}

Panel B: parameter estimates-GARCH process

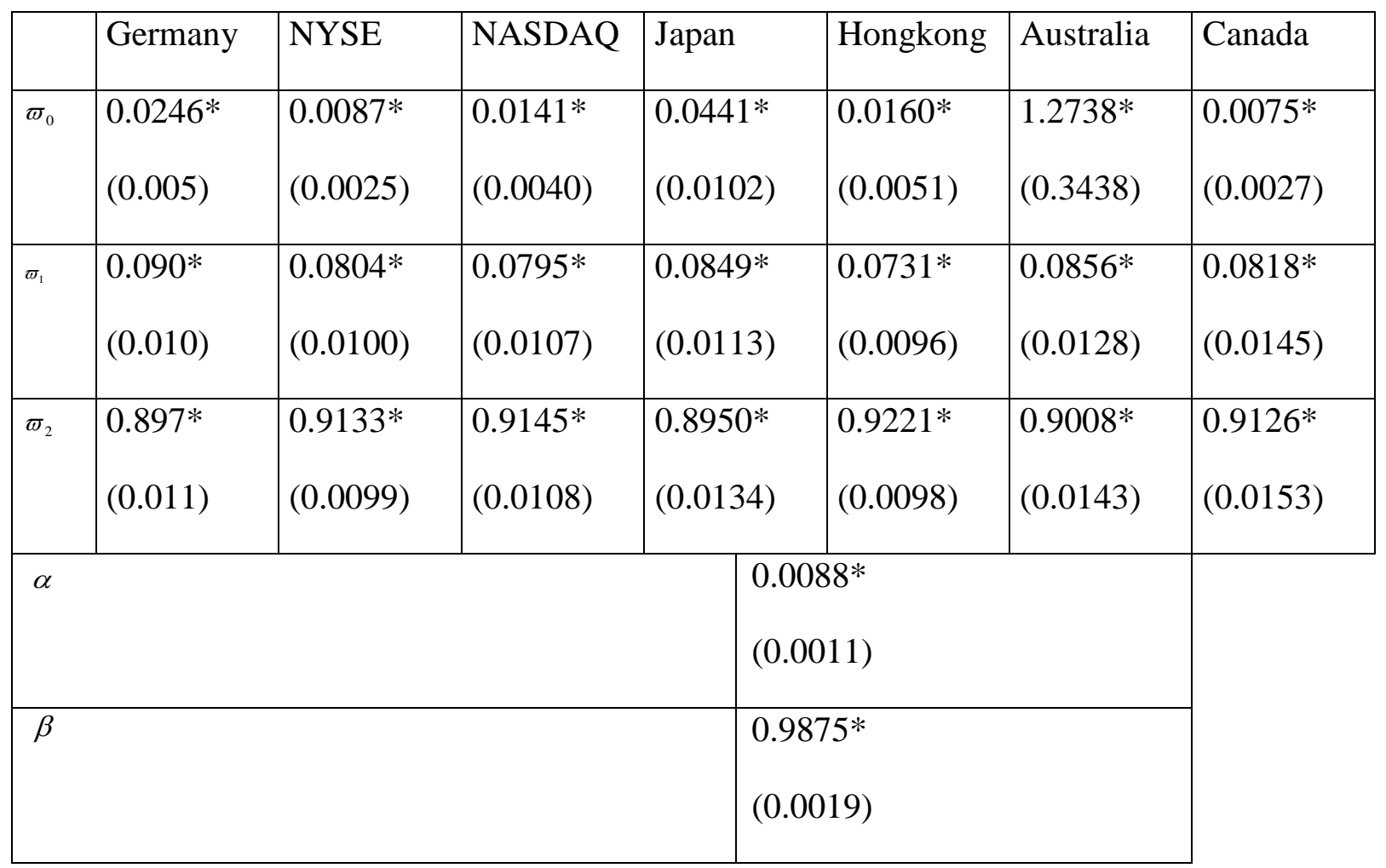


Panel C - Robust tests for model standardized residuals

\begin{tabular}{|l|l|l|l|l|l|l|l|}
\hline & Germany & NYSE & NASDAQ & Japan & Hongkong & Australia & Canada \\
\hline Skewness & $-0.305^{*}$ & $-0.513^{*}$ & $-0.382^{*}$ & $-0.1869^{*}$ & $-0.2657^{*}$ & $-0.377^{*}$ & $-0.619^{*}$ \\
\hline Kurtosis & $1.212^{*}$ & $2.147^{*}$ & $1.3143^{*}$ & $1.758^{*}$ & $1.9477^{*}$ & $1.376^{*}$ & $2.786^{*}$ \\
\hline JB & $417.07^{*}$ & $1281.6^{*}$ & $523.59^{*}$ & $726.56^{*}$ & $922.40^{*}$ & $557.78^{*}$ & $2104.3^{*}$ \\
\hline Q(12) & 6.1345 & $9.890^{*}$ & 1.152 & 1.235 & $12.248^{*}$ & $4.747^{*}$ & 5.655 \\
\hline Q $^{2}(12)$ & 9.077 & 20.267 & 26.289 & 0.625 & 15.223 & 13.207 & 2.078 \\
\hline
\end{tabular}

Notes: Bollerslev and Wooldridge (1992)'s robust standard errors are given in parentheses. $\varpi_{0}$ , $\varpi_{1}$ and $\varpi_{\varpi_{2}}$ refer to the parameters of a $\operatorname{GARCH}(1,1)$ process. The test for Kurtosis coefficient has been normalized to zero. JB is the Jarque-Bera test for normality based on excess skewness and Kurtosis. Q(12) is the Ljung-Box test for autocorrelation of order 12.ARCH is the Engle (1982)'s test for conditional heteroscedasticity. *, ** and *** indicate significance of coefficients at the $1 \%, 5 \%$ and $10 \%$ respectively.,+++ and +++ indicate rejection of the null hypotheses of no autocorrelation, normality and homocedasticity at the $1 \%, 5 \%$ and $1 \%$ levels of significance respectively for statistical tests.

Table 2 contains parameter estimates and a number of diagnostic tests for DCC-GARCH model. The coefficients relating the return series to the one-lag local (Panel A) are significant, except for Australia, Germany and NYSE. The ARCH coefficients and GARCH coefficients reported in panel $\mathrm{B}$ are significant for all countries. This is on line with previous results in the literature. The ARCH coefficients are relatively small in size, which indicates that conditional volatility does not change very rapidly. However, the GACH are large, indicating gradual fluctuations over time. In addition, the estimates coefficients $\alpha$ and $\beta$ satisfy the stationary conditions for all the variance and covariance processes

Diagnostics of standardized residuals are provided in panel C. ${ }^{3}$ One can remark that the indexes of kurtosis are often lower than those for the returns. However, the Bera-Jarque test statistics for normality indicates that the unconditional distribution of the conditionally normal GARCH process is not sufficiently fat-tailed to accommodate the excess kurtosis in the data. This result justifies the use of the QML procedures. We also compute the Lung-Box statistic to test the null hypothesis of absence of autocorrelation and the Engle (1982)'s test of absence of ARCH effects. The results indicate that the DCC-GARCH specification we use is flexible enough to capture the dynamics of the conditional covariance matrix.

\footnotetext{
${ }^{3}$ In the multivariate framework, the joint standardized residuals are given by $\varepsilon_{t}^{s}=H_{t}^{-1 / 2} \varepsilon_{t}$.
} 
Figure 3: Conditional Correlations of Germany with major stock markets
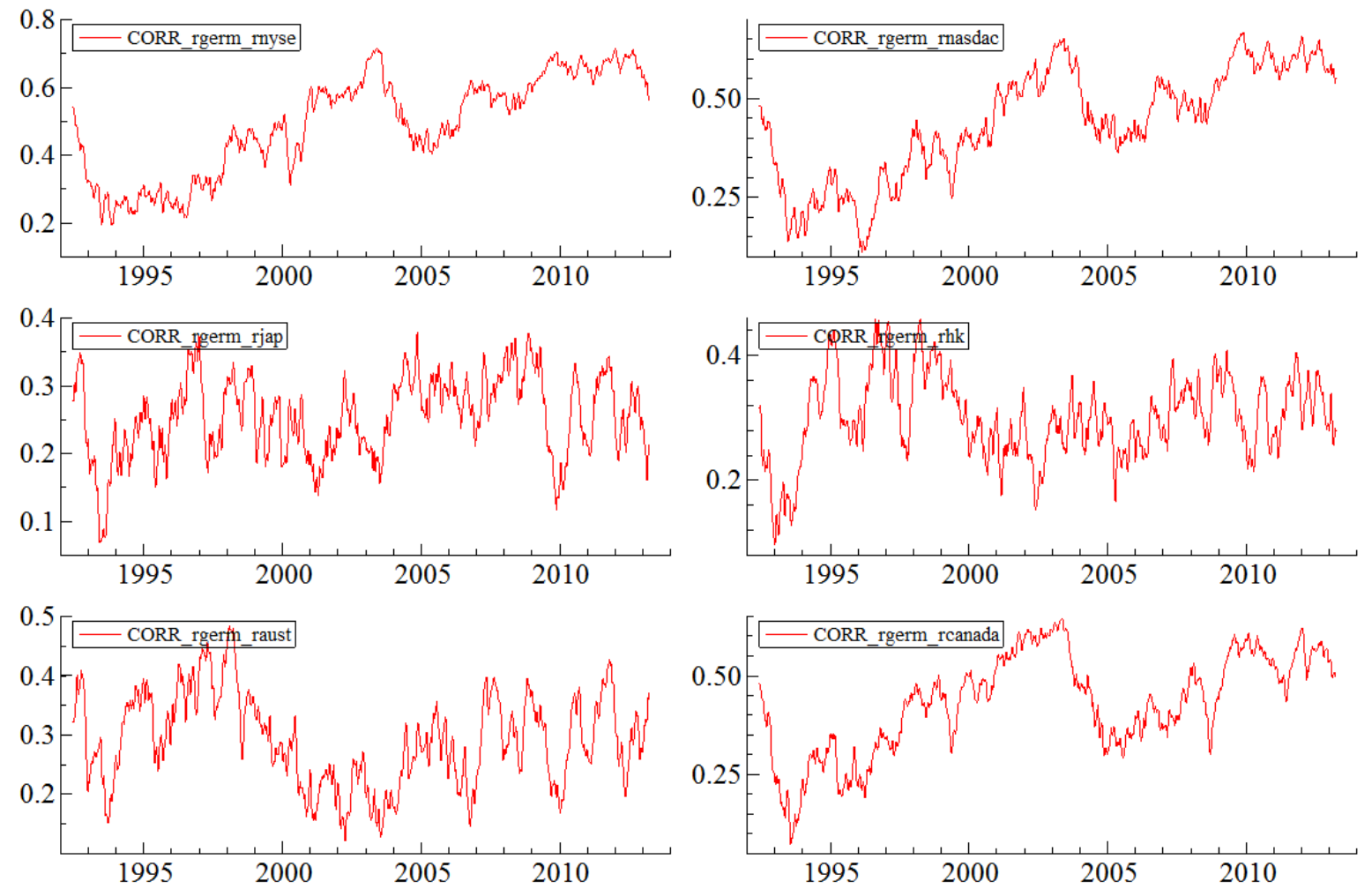

Table 3: Dynamic Conditional Correlations obtained from the DCC GARCH model

\begin{tabular}{|c|c|c|c|c|c|c|c|}
\hline & Germany & NYSE & NASDAQ & Japan & Hongkong & Australia & Canada \\
\hline Germany & 1 & & & & & & \\
\hline NYSE & $\begin{array}{l}0.540^{*} \\
(0.034)\end{array}$ & 1 & & & & & \\
\hline NASDAQ & $\begin{array}{l}0.482^{*} \\
(0.035) \\
\end{array}$ & $\begin{array}{l}0.897^{*} \\
(0.009) \\
\end{array}$ & 1 & & & & \\
\hline Japan & $\begin{array}{l}0.277^{*} \\
(0.039)\end{array}$ & $\begin{array}{l}0.148^{*} \\
(0.041)\end{array}$ & $\begin{array}{l}0.137^{*} \\
(0.042)\end{array}$ & 1 & & & \\
\hline Hongkong & $\begin{array}{l}0.317^{*} \\
(0.040) \\
\end{array}$ & $\begin{array}{l}0.196 * \\
(0.043) \\
\end{array}$ & $\begin{array}{l}0.170^{*} \\
(0.043) \\
\end{array}$ & $\begin{array}{l}0.417^{*} \\
(0.037) \\
\end{array}$ & 1 & & \\
\hline Australia & $\begin{array}{l}0.321^{*} \\
(0.041) \\
\end{array}$ & $\begin{array}{l}0.198^{*} \\
(0.043) \\
\end{array}$ & $\begin{array}{l}0.159^{*} \\
(0.043) \\
\end{array}$ & $\begin{array}{l}0.495^{*} \\
(0.032) \\
\end{array}$ & $\begin{array}{l}0.505^{*} \\
(0.034) \\
\end{array}$ & 1 & \\
\hline Canada & $\begin{array}{l}0.479 * \\
(0.034)\end{array}$ & $\begin{array}{l}0.738^{*} \\
(0.024)\end{array}$ & $\begin{array}{l}0.738^{*} \\
(0.024)\end{array}$ & $\begin{array}{l}0.168^{*} \\
(0.041)\end{array}$ & $\begin{array}{l}0.205^{*} \\
(0.0435) \\
\end{array}$ & $\begin{array}{l}0.207^{*} \\
(0.045)\end{array}$ & 1 \\
\hline
\end{tabular}

This section reports and interprets the results obtained from the estimation of our DCC GARCH model. We present the estimation results of the empirical model and investigate the dynamics of conditional correlations between markets. Dynamic conditional correlations within Germany with major stock market plotted in Figure 2. The average time-varying correlations are quite similar to the unconditional correlations reported in Table 1. However, the conditional correlations vary considerably over time and from a couple of countries to another. The average of correlations between the studied Germany and the NYSE is $54.0 \%$. 
This is highest conditional correlation between Germany and NYSE. The interesting features of this analysis Germany is more strongly attached with NYSE, NASDAQ and Canada compare to the Asian market Hong Kong and Japan. Germany with Australia is slightly stronger than Asian market like Japan and Hong Kong.

\section{Conclusion}

The co-movements of stock returns and volatilities are important in asset allocation and risk management. In this paper, continuous wavelet analysis employed to assess the comovements of German stock market returns with top stock markets in the world namely US, Canada, Japan and Australia. This methodology allows for the examination of the time-andfrequency varying co-movements of stock markets within a unified framework. We provide the evidence on global financial crisis on capital markets. The importance of wavelet analysis considering that international investors distinguish between short and long run relations for single time series, or for their association, allowing, thus, for a bivariate analysis.

The important implication of our findings is that, consistent with prior literature, the degree of stock market integration is changing over time. We detect a consistent change in the pattern of the relationship for all stock market pairs after 2000 where we note co-movements at relatively higher frequencies from prior frequency levels (Graham et. al, 2012). The debate in the literature as to whether the phenomenon of increased co-movement between international stock markets is permanent or temporary in nature, our findings suggest that the increase in stock co-movement of Germany with the developed markets in recent years contains both a permanent and a transitory component. The permanent component is attributed to the overall increasing trend toward global capital market integration documented in many studies (e.g., Ayuso and Blanco, 2001; Pukthuanthong and Roll, 2009).

Financial crisis in the observed period did uniformly increase co-movements between stock markets across all scales. The global financial crisis of 2007-2008 increased the already high level of co-movement between the observed stock market (Dajcmanet.al, 2012). The delay in responses found maybe an indication of arbitrage opportunities, a statement that deserves a more careful attention. The findings need further econometric development in order to guide practical portfolio investments. It would be worthwhile for future studies to explore how to combine wavelet analysis with the traditional portfolio analysis.

\section{References}

1. A'Hearn, B., and U. Woitek. (2001). More international evidence on the historical properties of business cycles. Journal of Monetary Economics 47 (2): 321-46. 
2. Aguiar-Conraria, L., Azevedo, N., \& Soares, M. J. (2008). Using wavelets to decompose the time-frequency effects of monetary policy. Physica A: Statistical mechanics and itsApplications, 387(12), 2863-2878.

3. Akoum, I., Graham, M., Kivihaho, J., Nikkinen, J.,\& Omran, M. (2012). Comovement of oil and stock prices in the GCC region: A wavelet analysis. The Quarterly Review of Economics and Finance, 52(4), 385-394.

4. Awokuse TO, Chopra A, Bessler DA. (2009). Structural change and international stock market interdependence: evidence from Asian emerging markets. Economic Modelling 26: 549-559.

5. Ayuso, J., \& Blanco, R. (2001). Has financial market integration increased during the nineties? Journal of International Financial Markets, Institutions and Money, 11, 265-287.

6. Bollerslev, T. (1986), 'Generalized Autoregressive Conditional Heteroscedasticity', Journal of Econometrics, 31, 307-327

7. Charles A, Darne' O. (2006). Large shocks and the september 11th terrorist attacks on international stock markets. Economic Modelling 23(4): 683-698.

8. Chudik, A., Fratzscher, M., (2011). Identifying the global transmission of the 20072009 financial crisis in a GVAR model. European Economic Review 55, 325-339

9. Dajcman, Silvo and Festic, Mejra and Kavkler, Alenka (2012): European stock market comovement dynamics during some major financial market turmoils in the period 1997 to 2010: a comparative DCC-GARCH and wavelet correlation, analysis, Applied Economics Letters, 19:13, 1249-1256

10. Dajcman, Silvo and Festic, Mejra and Kavkler, Alenka (2012): European stock market comovement dynamics during some major financial market turmoils in the period 1997 to 2010: a comparative DCC-GARCH and wavelet correlation, analysis, Applied Economics Letters, 19:13, 1249-1256

11. Engle, R.F. (1982), 'Autoregressive Conditional Heteroscedasticity with Estimates of the Variance of UK Inflation', Econometrica, 50, 987-1008.

12. Engle, R.F. (2002), 'Dynamic Conditional Correlation: a New Simple Class of Multivariate GARCH Models', Journal of Business and Economic Statistics, 20, 339350.

13. Fernandez, V. (2005). The international CAPM and a wavelet-based decomposition of value at risk. Studies in Nonlinear Dynamics \& Econometrics, 9(4), article 4.

14. Fernandez, V. (2006). The CAPM and value at risk at different time-scales. International Review of Financial Analysis, 15, 203-219.

15. Forbes K, Rigobon R. (2002). No contagion, only interdependence: measuring stock market co-movements. Journal of Finance 57: 2223-2261.

16. Graham, M., Kiviaho, J. and Nikkinen, J.( 2012) Integration of 22 emerging stock markets: a three dimensional analysis, Global Finance Journal, Vol. 23, pp. 34-47

17. Grauer R. R. and N. Hakansson, (1987) Gains from International Diversifications: 1968-85 Returns on Portfolios of Stocks and Bonds, Journal of Finance, 42(3), pp. 721-739. 
18. Grinsted, A., Moore, J.C. and Jevrejeva, S. (2004). Application of the cross wavelet transform and wavelet coherence to geophysical time series. Nonlinear Processes in Geophysics, 11,561-566.

19. Grubel, Herbert.G., (1968) Internationally Diversified Portfolios, American Economic Review, 58, December, pp. 1299-1314.

20. Guesmi, K., Nguyen, D.-K. and Teulon, F. (2013). Further evidence on the determinants of regional stock markets integration in Latin America, European Journal of Comparative Economics, Vol. 34 No. 1, pp. 397-413.

21. Hilliard, J. E. (1979), The Relationship Between Equity Indices on World Exchanges, Journal of Finance, 34, pp. 103-114.

22. Hon, M.T., Strauss, J., and Yong, S., (2004). Contagion in Financial Markets After September 11 - Myth or Reality? Journal of Financial Research 27, 95-114.

23. Kenourgios, D., Samitas, A., Paltalidis, N., (2011). Financial crises and stock market contagion in a multivariate time-varying asymmetric framework. Journal of International Financial Markets, Institutions \& Money 21, 92-106.

24. Kiviaho, J., Nikkinen, J., Piljak, V., \& Rothovius, T. (2012). The Co-movement Dynamics of European Frontier Stock Markets. European Financial Management.

25. Kizys, R., and C. Pierdzioch. 2009. Changes in the international comovement of stock returns and asymmetric macroeconomic shocks. Journal of International Financial Markets, Institutions and Money 19 (2): 289-305.

26. Loh, L.(2013) Co-movement of Asia-Pacific with European and US stock market returns: A crosstime-frequency analysis, Research in International Business and Finance, 29: 1- 13

27. Longin, F., \& Solnik, B. (2001). Extreme correlation of international equity markets. Journal ofFinance, 56, 649-676.

28. Lundblad, C. (2007), 'The Risk Return Tradeoff in the Long Run: 1836-2003', Journal of Financial Economics, 85, 123-150.

29. Markowitz, H. M. (1952) Portfolio Selection. Journal of Finance7, 1: 77-91.

30. Pakko, M. (2004). A spectral analysis of the cross-country consumption correlation puzzle. Economics Letters 84 (3): 341-7.

31. Pukthuanthong, K. and Roll, R., (2008) Global market integration: an alternative measure and its application', Journal of Financial Economics, Vol. 94, pp. 214-32

32. Ramsey, J., \& Zhang, Z. (1996). The application of wave form dictionaries to stock market index data. In Y. Kratsov, \& J. Kadtke (Eds.), Predictability of complex dynamical systems. Springer.

33. Ramsey, J., \& Zhang, Z. (1997). The analysis of foreign exchange data using waveform dictionaries. Journal of Empirical Finance, 4, 341-372.

34. Ramsey, J., \&Lampart, C. (1998a). Decomposition of economic relationships by time scale using wavelets. Macroeconomic Dynamics, 2(1), 49-71.

35. Ramsey, J., \&Lampart, C. (1998b). The decomposition of economic relationships by time scale using wavelets: Expenditure and income. Studies in Nonlinear Dynamics \& Econometrics, 3(1), 23-42. 
36. Ranta, M. (2009). Contagion among major world markets: A wavelet approach. Paper presented at the 21st Annual Conference of Northern Finance Association, September 25-27, Niagara-on-the-Lake, Ontario, Canada

37. Rigobon, R., (2003). Identification through Heteroskedasticity. Review of Economics and Statistics 85 (4), 777-792.

38. Rua, A. (2010). Measuring comovement in time-frequency space. Journal of Macroeconomics, 32, 685-691

39. Rua, A. and Nunes, L. C. (2012) A wavelet-based assessment of market risk: the emerging markets case, Quarterly Review of Economics and Finance, 52, 84-92

40. Rua, A. and Nunes, L.C. (2005) Coincident and leading indicators for the euro area: a frequency band approach, International Journal of Forecasting, 21, 503-23.

41. Rua, A., \& Nunes, L. C. (2009). International comovement of stock returns: A wavelet analysis. Journal of Empirical Finance, 11, 632-639.

42. Schwert, G. W. (2011). Stock volatility during the recent financial crisis.European Financial Management, 17(5), 789-805.

43. Syllignakis, M. N., and Kouretas, G. P. (2011). Dynamic correlation analysis of financial contagion: Evidence from the Central and Eastern European markets. International Review of Economics and Finance 20(4), 717-732.

44. Taylor, MP and Tonks, I. (1989). The internationalisation of stock markets and the abolition of UK exchange control. Review of Economics and Statistics 71: 332-336.

45. Tiwari, A. K., Dar, A. B., \& Bhanja, N. (2013). Oil price and exchange rates: A wavelet based analysis for India. Economic Modelling, 31, 414-422.

46. Tiwari, A.K., (2012). Oil prices and the macroeconomy reconsideration for Germany: using continuous wavelet. Economic Modelling. 30, 636-642.

47. Tonn,V.L and Li, H.C. and McCarthy, Joseph (2010) Wavelet domain correlation between the futures prices of natural gas and oil, The Quarterly Review of Economics and Finance 50, 408-414

48. Torrence, C., Compo, G.P., (1998). A practical guide to wavelet analysis. Bulletin of the American Meteorological Society 79, 605-618.

49. Uddin, Gazi Salah and Tiwari, Aviral Kumar. (2013). Measuring co-movement of oil price and exchange rate differential in Bangladesh. Economics Bulletin, 33(3). 19221930

50. Uddin, Gazi Salah and Sjö, Bo (2013) Business Cycle Synchronization between Germany and Countries Inside and Outside Euro area, Swedish Network for European Studies in Economics and Business (SNEE)

51. Vacha, L. and Barunik, J. (2012), Co-movement of energy commodities revisited: evidence from wavelet coherence analysis, Energy Economics, Vol. 34 No. 1, pp. 241247. 